\title{
A Numerical Taxonomical Study of Some Corynebacteria and Related Organisms
}

\author{
BY B. J. HARRINGTON* \\ Department of Virology and Bacteriology, University of Birmingham \\ SUMMARY
}

A numerical Adansonian analysis has been performed on the results of a wide range of biochemical and physiological characters of organisms at present classified in the genera Corynebacterium, Mycobacterium, Nocardia, Arthrobacter and Jensenia. The results show that some of the organisms need to be reclassified. Corynebacterium ulcerans could be considered as another type of $C$. diphtheriae, and $C$. pyogenes and $C$. haemolyticum have little similarity to any of the other corynebacteria. Corynebacterium equi and Jensenia canicruria appear to be closely related to the mycobacteria examined. The plant pathogens $C$. rathayi, $C$. betae and $C$. michiganense seem to be distinct from most of the animal parasites in this genus. The mycobacteria, nocardia and most of the corynebacteria from animal sources form one large group at the $51 \%$ similarity level. Acid-fastness does not seem to be a good criterion for separating the genus Corynebacterium from the genus Mycobacterium, some of the corynebacteria showed varying degrees of acid-fastness.

\section{INTRODUCTION}

In the genus Corynebacterium, Bergey's Manual (1957) lists thirty-three species. In addition to these there are others which have been described, and some which have been transferred from this genus to other genera in Bergey's Manual or by other authors, but which are still retained as corynebacteria in culture collections and by some authors. Several workers have suggested that the genus Corynebacterium contains some species, particularly those from plant and soil sources, which should not be there (Conn, 1947; Conn \& Dimmick, 1947; Clark, 1952; Cummins, 1962 $a$; da Silva \& Holt, 1965). Cummins (1962b) and Perkins \& Cummins (1964) found that most of the plant pathogens they examined had markedly different cellwall compositions from those of the animal parasites in the genus. Harrington (unpublished) has found that $C$. michiganense has a cell-wall amino acid composition similar to those of most of the other plant pathogens, while the soil strain C. fimi has the amino acid pattern of the animal parasites.

Not only is there confusion within the genus Corynebacterium, but also disagreement as to its taxonomic position in relation to other genera, notably Mycobacterium and Nocardia. Mainly on the basis of acid-fastness, Bergey's Manual (1948) transferred the genus Corynebacterium to a new family, Corynebacteriaceae, in the Eubacteriales, the genera Mycobacterium and Nocardia remaining in the Actinomycetales. The seventh edition of Bergey's Manual (1957) continued this division, although Bisset \& Moore (1949), Jensen (1953) and others had pointed out that

* Present address : Department of Bacteriology. University of Wisconsin, Madison, Wis., 53706, U.S.A. 
morphologically these three genera are closely related and not always distinct from each other. Cummins \& Harris (1958) found that these genera have almost identical patterns of cell-wall components, and Kwapinski $(1956,1964)$ and Cummins (1962b) have shown serological relationships between members of these genera.

This present work includes an Adansonian numerical study of the taxonomy of some species currently classified as corynebacteria, and of the relationships of these organisms to others in some related genera.

\section{METHODS}

Strains examined. Table 1 shows the origins of the strains used in this study. Those received from culture collections have the names they bore when they were received, those from the Department's collection have the names under which they are maintained.

Table 1. The strains used and their sources

From the National Collection of Type Cultures

$\begin{array}{lrlr}\text { Corynebacterium equi } & \mathbf{1 6 2 1} & \text { C. } \text { diphtheriae gravis } & \mathbf{7 2 8 3} \\ \text { C. diphtheriae P.w. } & \mathbf{3 8 0} & \text { C. } \text { hofmannii } & \mathbf{2 3 1} \\ \text { C. renale } & \mathbf{7 4 4 8} & \text { C. } \text { bovis } & \mathbf{3 2 2 4} \\ \text { C. flavidum } & \mathbf{7 4 6} & \text { C. } \text { xerosis } & \mathbf{7 2 4 3} \\ \text { C. } \text { ulcerans } & \mathbf{8 6 4 0} & \text { C. } \text { ovis } & \mathbf{4 6 8 1} \\ \text { C. } \text { segmentosum } & \mathbf{9 3 4} & \text { C. } \text { murium } & \mathbf{9 4 9} \\ \text { C. fimi } & \mathbf{7 5 4 7} & \text { C. viscosum } & \mathbf{2 4 1 6} \\ \text { C. } \text { haemolyticum } & \mathbf{8 4 5 2} & \text { C. } \text { pyogenes } & \mathbf{9 8 2 5}\end{array}$

From the National Collection of Plant Pathogenic Bacteria
C. fascians
764
C. betae
C. rathayi
797
C. michiganense

From the National Collection of Dairy Organisms

$\begin{array}{llll}\text { C. } \text { helvolum } & 1192 & \text { Arthrobacter sp. } & 1233 \\ \text { Arthrobacter sp. } & 1234 & & \end{array}$

From the Department's collection

$\begin{array}{ll}\text { C. diphtheriae intermedius } & \text { C. diphtheriae mitis } \\ \text { C. hofmannii } & \text { Mycobacterium phlei } \\ \text { M. lacticola } & \text { M. smegmatis } \\ \text { M. butyricum } & \text { Jensenia canicruria }\end{array}$

Isolated by the author

Nocardia sp. from human saliva Nocardia sp. from soil

Strain maintenance. The strains were maintained in a medium of the following composition, percentages are w/v. Tryptone (Oxoid L42) $0.5 \%$, proteose peptone (Oxoid L 46) $\mathbf{0} \cdot 25 \%$, casein hydrolysate (Allen and Hanbury Ltd., acid hydrolysed, vitamin-free) $\mathbf{0} .25 \%, \mathrm{NaCl} 0.1 \%, \mathrm{KH}_{2} \mathrm{PO}_{4} \mathbf{0 . 0 2} \%, \mathrm{Na}_{2} \mathrm{HPO}_{4} \mathbf{0 . 0 6} \%, \mathrm{MgSO}_{4}$ $0.001 \%, \mathrm{MnCl}_{2} 0.001 \%$. The $\mathrm{pH}$ was adjusted to $7 \cdot 2$. This medium supported good growth of all the strains.

Characters examined. Table 2 shows the characters examined. With the exception of the Voges-Proskauer test, the methyl red test, reactions in litmus milk, growth in Koser citrate, growth on Hoyle medium, and liquefaction of heat-coagulated serum, all the tests were performed using the maintenance medium as the basal nutrient 
Table 2. Characters examined

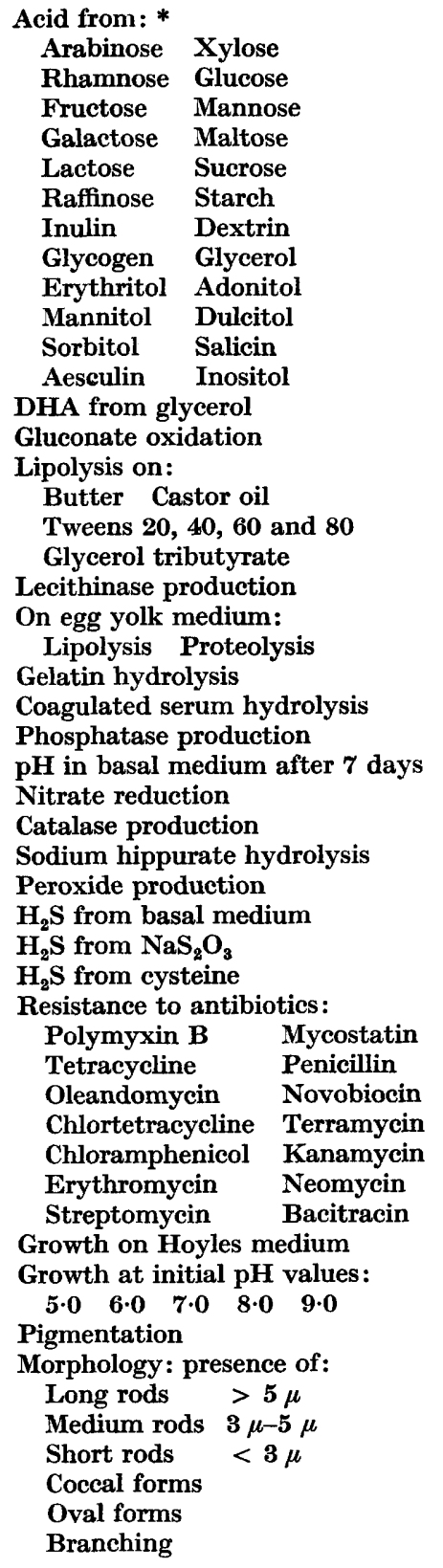

Methyl red test

Voges-Proskauer test

Salicin hydrolysis

Aesculin hydrolysis

Starch hydrolysis

Reactions in litmus milk

Oxid. or ferm. of glucose

Polysaccharide on medium + Glucose Sucrose

Intracellular starch on medium + Glucose Sucrose

Growth in Koser citrate

Acetic acid from ethanol

Calcium lactate oxidation

Tyrosine breakdown

Xanthine breakdown

Lysine decarboxylation

Ornithine decarboxylation

Phenylalanine deamination

Sodium malonate utilisation

Ammonia from arginine

Serum hydrolysis

Casein hydrolysis

Ammonia from basal medium

Urease production

Nitrite reduction

Oxidase production

Methylene blue reduction

Benzidine $/ \mathrm{H}_{2} \mathrm{O}_{2}$ test

Haemolysis of horse blood

Motility

Anaerobic growth

Reaction to the Gram stain

Tolerance of NaCl: $\mathbf{2 . 5} \% \quad \mathbf{5 . 0} \% \quad \mathbf{1 0 . 0} \%$

Tolerance of potassium tellurite: $0.0175 \% \quad 0.035 \%$

Tolerance of sodium selenite: $0.0175 \% \quad 0.035 \%$

Tolerance of triphenyltetrazolium chloride: $\begin{array}{llll}0.001 & 0.0025 \% & 0.01 \% & 0.025 \%\end{array}$

Tolerance of sodium taurocholate: $\mathbf{2 . 0} \% \quad 5.0 \%$

Growth at:

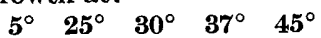

On basal medium, acid-fast to: $\mathrm{H}_{2} \mathrm{SO}_{4} \quad 1 \% \quad 2 \% \quad 5 \% \quad 10 \% \quad 20 \%$

On basal medium $+2 \%$ glycerol, acid-fast to: $\begin{array}{lllllll}\mathrm{H}_{2} \mathrm{SO}_{4} & 1 \% & 2 \% & 5 \% & 10 \% & 20 \%\end{array}$

* No strain produced gas from any carbohydrate.

medium. The strains from animal sources were incubated at $37^{\circ}$, all the others at $30^{\circ}$. For complete details of the test procedures, see Harrington (1964).

For the numerical analysis, all the characters, with the exceptions listed below, were recorded as positive or negative. Pigmentation was scored as white, creamy 
yellow, pink or orange; haemolysis as $\alpha, \beta$, or negative; $\mathrm{pH}$ of the basal medium after 7 days as no change, raised or lowered; reactions in litmus milk as acid, acid with clot, no change, or alkaline; digestion and reduction of the indicator were scored as positive or negative; pathway of glucose breakdown, where applicable, as oxidation or fermentation. To make the processing of the results, which was done by hand, easier, degrees of positivity were not taken into account. All the characters were given equal weight and the equation proposed by Sneath (1957) was used to obtain the similarity values. This equation is $\mathrm{S}=a /(b+c+a)$, where $a=$ the number of tests in which both members of a pair are positive, $b+c=$ the number of tests in which one member is positive and the other negative, and negative matches are not included.

Acid-fastness. Two days' growth on the maintenance medium and on the maintenance medium $+2 \%$ glycerol was used. Smears were made on microscope slides and stained for 5 min. with hot strong carbol fuchsin, then washed with water and treated with four changes of sulphuric acid, each application lasting $1.5 \mathrm{~min}$. The acid was washed off the slide with water and the smear blotted dry between each acid change. After the last washing the smears were counter-stained with dilute malachite green. The first concentration of acid used was $1 \%$. Smears were then made of those strains which showed more than approximately $25 \%$ of the cells retaining the carbol fuchsin, and these were stained as before, with $2 \%$ acid being used to effect decolorization. This process of elimination was repeated with $\mathbf{5} \%$ acid, $10 \%$ acid and $20 \%$ acid until complete or almost complete decolorization was achieved.

\section{RESULTS}

Numerical analysis. After the similarity values had been calculated as percentages, a cluster analysis was performed as described by Sneath (1962), a strain being admitted to a group at the highest similarity level it had with any member of that group. Figure 1 is the similarity matrix after the cluster analysis had been performed, and Figure $\mathbf{2}$ is the dendrogram derived from the similarity matrix.

The main points of interest are:

(1) The relatively wide range of $\mathbf{S}$ values among the strains of Corynebacterium diphtheriae.

(2) The high $\mathrm{S}$ values of Corynebacterium ulcerans with the 'gravis' and 'mitis' strains of $C$. diphtheriae.

(3) Corynebacterium pyogenes and $C$. haemolyticum have very low $\mathrm{S}$ values with all the other strains examined here.

(4) Jensenia canicruria and Corynebacterium equi come within the mycobacterium group.

(5) The plant pathogens with the atypical cell wall patterns, Corynebacterium rathayi, C. betae and C. michiganense, have low $\mathrm{S}$ values with most of the corynebacteria from animal sources, and these values are lower than those of the other plant pathogen, C. fascians, particularly with the strains of $C$. diphtheriae.

(6) The mycobacteria, the nocardia and the majority of the animal parasitic corynebacteria are in one group at the $51 \% \mathrm{~S}$ level.

Acid-fastness. Table 3 shows the results of the acid-fast staining of those strains which showed any degree of acid-fastness on either medium. Most of those that 


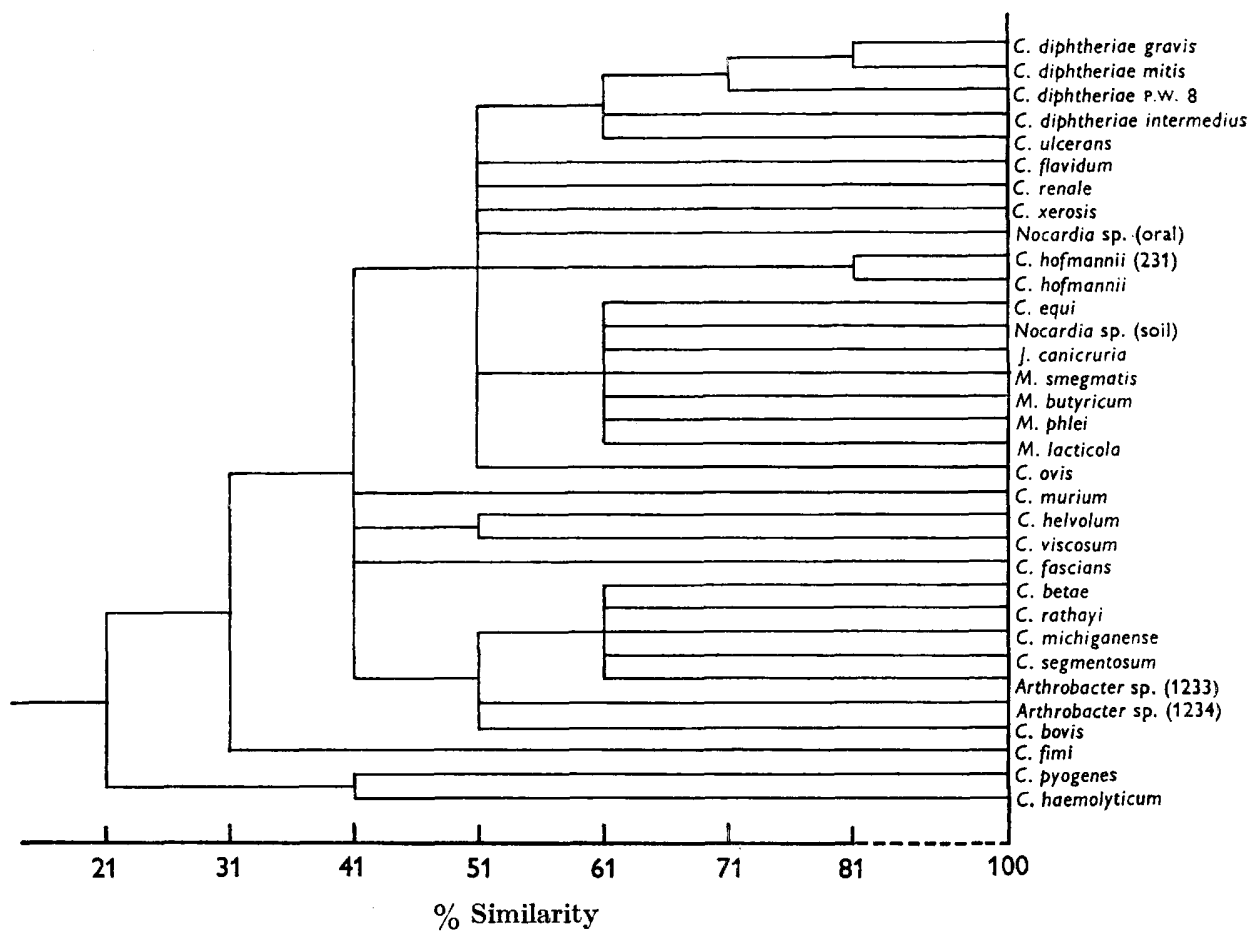

Fig. 2. Dendrogram obtained from the similarity matrix.

Table 3. Acid-fastness of strains grown on different media

\begin{tabular}{|c|c|c|c|c|c|c|c|c|c|c|}
\hline \multirow[b]{2}{*}{ Concentration of $\mathrm{H}_{2} \mathrm{SO}_{4}$} & \multicolumn{5}{|c|}{ Maintenance medium } & \multicolumn{5}{|c|}{$\begin{array}{l}\text { Maintenance medium } \\
+2 \% \text { glycerol }\end{array}$} \\
\hline & $1 \%$ & $2 \%$ & $5 \%$ & $10 \%$ & $20 \%$ & $1 \%$ & $2 \%$ & $5 \%$ & $10 \%$ & $20 \%$ \\
\hline C. diphtheriae gravis & + & + & - & - & - & + & + & + & - & - \\
\hline C. diphtheriae mitis & + & - & - & - & - & + & + & + & - & - \\
\hline C. diphtheriae P.w. 8 & + & + & + & - & - & + & + & + & - & - \\
\hline C. ulcerans & + & - & - & - & - & + & + & + & - & - \\
\hline C. flavidum & - & - & - & - & - & + & - & - & - & - \\
\hline C. renale & - & - & - & - & - & + & - & - & - & - \\
\hline Nocardia sp. (oral) & + & + & - & - & - & + & + & + & + & - \\
\hline C. hofmannii (231) & + & - & - & - & - & + & - & - & - & - \\
\hline Nocardia sp. (soil) & + & - & - & - & - & + & - & - & - & - \\
\hline Jensenia canicruria & + & + & - & - & - & + & + & - & - & - \\
\hline M. smegmatis & + & + & + & - & - & + & + & + & + & - \\
\hline M. phlei & + & + & + & - & - & + & + & + & + & - \\
\hline M. butyricum & + & + & - & - & - & + & + & + & + & - \\
\hline M. lacticola & + & + & + & - & - & + & + & + & + & - \\
\hline C. helvolum & - & - & - & - & - & + & - & - & - & - \\
\hline
\end{tabular}

showed some resistance to decolorisation when grown on the maintenance medium showed an increased resistance when grown on this medium $+2 \%$ glycerol. Even on the glycerol-containing medium all the mycobacteria examined were decolorized by $20 \%$ sulphuric acid, while on this medium C. ulcerans and the 'gravis', 'mitis' and P.W. 8 strains of $C$. diphtheriae were resistant to $5 \%$ acid. 


\section{DISCUSSION}

Among the four strains of Corynebacterium diphtheriae there is a range of similarity values, from $87 \%$ for the 'gravis + mitis' pairing down to $51 \%$ for the intermedius + P.w. 8 pairing, the lowest values being those of pairings which include the 'intermedius' strain. In view of this wide range of $S$ values, the position of $\boldsymbol{C}$. ulcerans, which has been found to cause diphtheria-like lesions and produce a similar toxin to that of $C$. diphtheriae (see Wilson \& Miles, 1964), is of interest. It was found here that this organism has an $\mathrm{S}$ value of $62 \%$ with the 'mitis' strain and $60 \%$ with the 'gravis' strain. The taxonomic rank of $C$. ulcerans is still a matter of some dispute. Saxholm (1951) and Henricksen \& Grelland (1952) thought the organisms of the $C$. ulcerans type, the so-called 'diphtheria-like corynebacteria', could either be regarded as a distinct species or as a variety of $C$. diphtheriae. Howard \& Jann (1954) felt that their results with bacteriophages lytic for the diphtheria-like corynebacteria showed these organisms to be distinct from $C$. diphtheriae, although two of their diphtheria-like corynebacteria resembled $C$. diphtheriae in that they were resistant to all the phages used. Wilson \& Miles (1964) believed that $C$. ulcerans is sufficiently well defined to qualify for species rank, basing their decision on the results of Jebb (1948) who found it to differ from C. diphtheriae in only four characters. If the four strains of $C$. diphtheriae examined here are to be regarded as representatives of one species, then on the $S$ values of the 'gravis' and 'mitis' strains with $C$. ulcerans found here, this organism should be reclassified as a variety of $C$. diphtheriae.

Corynebacterium pyogenes and C. haemolyticum were found by Cummins \& Harris (1956) to have cell-wall amino acid and sugar patterns characteristic of the streptococci, not the corynebacteria, and they suggested that these organisms should be reclassified as streptococci. The similarity values of these two strains with all the other strains are low, which supports the hypothesis that they are not corynebacteria. Sneath \& Cowan (1958), in their numerical taxonomical study of a wide range of bacteria, found that $C$. pyogenes fell in the group which contained the streptococci.

There is a distinct group at the $61 \%$ level made up of the mycobacteria, Corynebacterium equi, Jensenia canicruria, and the soil strain of Nocardia. The results for the mycobacteria are in general agreement with those of Cerbon \& Bojalil (1961), who found that Mycobacterium smegmatis and $M$. phlei were on the same branch of their dendrogram, the branch dividing at the $60 \%$ level into two groups. It is of interest here that $C$. equi and $J$. canicruria appear in the mycobacteria group. Jensen (1934) placed $C$. equi in the genus Mycobacterium because of its acid-fastness, and Jensen (1952) considered that its existence showed that there was a close relationship between the genera Corynebacterium and Mycobacterium. The strain examined here showed no trace of acid-fastness. The genus Jensenia was proposed by Bisset \& Moore (1949) to include the unicellular soil diphtheroids, but J. canicruria, described by these authors in 1950, has never gained much support as a specific entity, being identified as a nocardia by some authors and as a mycobacterium by others (see Adams \& McClung, 1960; Gordon \& Mihm, 1961; Kwapinski, 1964; Jones \& Bradley, 1964). Sneath \& Cowan (1958) found it to be in the mycobacterium group of their numerical taxonomy. 
Corynebacterium rathayi, $C$. betae and $C$. michiganense appear to be more distinct from most of the animal parasitic corynebacteria, particularly those of the $C$. diphtheriae group, than do C. fascians and C. fimi, and this distinction is similar to that found with the cell-wall composition patterns of these organisms. Da Silva \& Holt (1965) have compared some plant pathogens with $C$. diphtheriae and they concluded that the plant pathogens were sufficiently distinct from $C$. diphtheriae to warrant their exclusion from the genus Corynebacterium. They suggested that C. fascians, being so different from all the other coryneforms they examined, should be excluded from the family Corynebacteriaceae, a proposal the present author cannot agree with. Of the plant pathogens, C. fascians appears from the numerical taxonomy presented here, to be the one most closely related to the animal strains, a relationship that is also suggested by the cell-wall studies of Cummins (1962b).

The position of two of the strains from animal sources cannot be readily explained. Corynebacterium segmentosum, a species no longer recognised by Bergey's Manual (1957), is from the human respiratory tract, and $C$. bovis is commonly found in cow's milk, yet both fall into the Arthrobacter-plant pathogens group at the $51 \%$ level of the dendrogram.

The large group at the $51 \%$ level contains almost all the strains with the cell-wall composition which Cummins \& Harris (1958) and Cummins (1962b) found to be typical of the true corynebacteria, the mycobacteria and the nocardias, and their presence in this group could further indicate a close relationship between these three genera.

In the distinction between and the separation of the genera Corynebacterium and Mycobacterium, the character of acid-fastness has always been a major factor, the corynebacteria being described as non-acid-fast and the mycobacteria as acid-fast. However, 'acid-fast' does not seem to be a well-defined term, and although its meaning is clear in medical laboratory procedure referring to $\boldsymbol{M}$. tuberculosis, it is not always certain that the same exact meaning is used for other species of this genus and other genera. Bergey's Manual (1957) uses such descriptions as 'weakly acid-fast', 'acid-fast when grown under the proper conditions' and 'not as strongly acid-fast as . . .', which confirm the idea that the criterion of acid-fastness is not a sound taxonomic one. This is further supported by the results of the acid-fast staining reported here, in which the 'gravis', 'mitis' and P.w. 8 strains of C. diphtheriae, and $C$. ulcerans were resistant to decolorization by $5 \%$ sulphuric acid when grown in the presence of $2 \%$ glycerol, and on this medium the oral nocardia was as acid-fast as the four mycobacteria.

The results of this present work, taken with the results of Kwapinski (1956, 1964), Cummins \& Harris (1958) and Cummins (1962b), and the morphology of these organisms, lead the present author to support the suggestion, made by Cummins $(1962 a)$ on the basis of cell wall composition, that the genera Corynebacterium, Mycobacterium and Nocardia could be merged to form one genus. Even if this is not generally accepted, there is no reason to continue the separation of the genus Corynebacterium from the genera Mycobacterium and Nocardia into different orders mainly on the basis of acid-fastness. 


\section{REFERENCES}

Adams, J. N. \& McClung, N. M. (1960). Morphological studies in the genus Nocardia. V. Septation in Nocardia rubra and Jensenia canicruria. J. Bact. 80, 281.

Bergey's Manual of Determinative Bacteriology. (1948). 6th ed. Ed. by R. S. Breed, E. G. D. Murray and A. P. Hitchens. Baltimore: Williams and Wilkins Co.

Bergey's Manual of Determinative Bacteriology. (1957). 7th ed. Ed. by R. S. Breed, E. G. D. Murray and N. R. Smith. Baltimore: Williams and Wilkins Co.

Bisset, K. A. \& Moore, F. W. (1949). The relationships of certain branched bacterial genera. J. gen. Microbiol. 3, 387.

Bisset, K. A. \& Moore, F. W. (1950). Jensenia, a new genus of the Actinomycetales. J. gen. Microbiol. 4, 280.

Cerbon, J. \& Bojall, L. F. (1961). Physiological relationship of rapidly growing mycobacteria. Adansonian classification. J. gen. Microbiol. 25, 7.

Clark, F. E. (1952). The generic classification of soil corynebacteria. Int. Bull. bact. Nomencl. Taxon. $2,45$.

Cons, H. J. (1947). A protest against the misuse of the generic name Corynebacterium. J. Bact. 54, 10.

Cons, H. J. \& Drmmick, I. (1947). Soil bacteria similar in morphology to Mycobacterium and Corynebacterium. J. Bact. 54, 291.

Cummins, C. S. (1962a). Immunochemical specificity and the location of antigens in the bacterial cell wall. Symp. Soc. gen. Microbiol. 12, 212.

Cummins, C. S. $(1962 b)$. Chemical composition and antigenic structure of the cell walls of Corynebacterium, Mycobacterium, Nocardia, Actinomyces and Arthrobacter. J. gen. Microbiol. 28, 35.

Cummins, C. S. \& Harris, H. (1956). The chemical composition of the cell wall in some Gram positive bacteria and its possible value as a taxonomic character. J. gen. Microbiol. $14,583$.

Cummins, C. S. \& Harris, H. (1958). Studies on cell-wall composition and taxonomy of Actinomycetales and related groups. J. gen. Microbiol. 18, 173.

Da Silva, G. A. N. \& Holt, J. G. (1965). Numerical taxonomy of certain coryneform bacteria. J. Bact. $90,921$.

Gordon, R. E. \& Mrнm, J. M. (1961). The specific identity of Jensenia canicruria. Canad. J. Microbiol. 7, 108.

HARRington, B. J. (1964). The taxonomy of oral corynebacteria. University of Birmingham; Ph.D. Thesis.

Henricksen, S. D. \& Grelland, R. (1952). Toxigenicity, serological reactions and relationships of the diphtheria-like corynebacteria. J. Path. Bact. 64, 503.

Howard, D. H. \& JANN, G. J. (1954). The isolation and characterization of bacteriophage active against the diphtheria-like corynebacteria. J. Bact. 68, 316.

JEBB, W. H. H. (1948). Starch-fermenting, gelatin-liquefying corynebacteria isolated from the human nose and throat. J. Path. Bact. 60, 403.

Jensen, H. L. (1934). Studies on the saprophytic mycobacteria and corynebacteria. Proc. Linn. Soc. N.S.W. 59, 19.

Jensen, H. L. (1952). The coryneform bacteria. A. Rev. Microbiol. 6, 77.

Jensen, H. L. (1953). The genus Nocardia (or Proactinomyces) and its separation from the other Actinomycetales, with some reflections on the phylogeny of the Actinomyces. Proc. 6th int. Congr. Microbiol. 6, 69.

Jones, L. A. \& Bradley, S. G. (1964). Relationships among the streptomyces, nocardiae, mycobacteria and other actinomycetes. Mycologia 61, 505.

Kwapinski, J. B. (1956). Antigenic relationships between the genera Mycobacterium and Corynebacterium. Bull. Acad. Pol. Sci. 4, 379.

Kwapinski, J. B. (1964). Cytoplasmic antigen relationships among the Actinomycetales. J. Bact. 87, 1234 .

Perkins, H. R. \& Cummins, C.S. (1964). Chemical structure of bacterial cell walls. Nature, Lond. 201, 1105. 
Saxholm, R. (1951). Toxin-producing diphtheria-like organisms isolated from cases of sore throat. J. Path. Bact. 63, 303.

Sneath, P. H. A. (1957). The application of computers to taxonomy. J. gen. Microbiol. 17, 201.

SNeath, P. H. A. (1962). The construction of taxonomic groups. Symp. Soc. gen. Microbiol. $12,289$.

Sneath, P. H. A. \& Cowan, S. T. (1958). An electro-taxonomic survey of bacteria. J. gen. Microbiol. 19, 551.

Topley and Wilson's Principles of Bacteriology and Immunity (1964). 5th ed. Ed. by G. S. Wilson and A. A. Miles. London: E. Arnold Ltd. 